\title{
Clinical and Radiological Evaluation of Marginal Bone Loss around Dental Implants Restored with Zirconium vis-à-vis Porcelain Fused to Metal: An In Vivo Study
}

\author{
Udey Singh Wirring ${ }^{1}$ Tarun Kalra ${ }^{1} \quad$ Manjit Kumar ${ }^{1}$ \\ 1Department of Prosthodontics, Bhojia Dental College and Hospital,
Baddi, Solan, Himachal Pradesh, India
}

Ajay Bansal ${ }^{1} \quad$ Aquib Javaid ${ }^{1}$

Address for correspondence Manjit Kumar, MDS, Department of Prosthodontics, Bhojia Dental College, Baddi, Solan 173205, Himachal Pradesh, India (e-mail: manjitkiran@yahoo.co.in.com).

Dent J Adv Stud 2020;8:17-21

\begin{abstract}
Introduction Marginal bone level is the criterion for implant success. Patient expectations for more natural looking implant restorations created the need to restore implants with more esthetically pleasing materials like Zirconia rather than conventional porcelain-fused to-metal (PFM) crowns. The aim of this study was to evaluate marginal bone loss around dental implants clinically and radiographically when restored with Zirconia and PFM prosthesis.

Keywords

- dental implant

- fixed partial dentures

- marginal bone loss

- radiographic evaluation

- superstructure materials

Materials and Methods Two groups (control and test) were formed with 14 patients each. In the control group, the subjects were rehabilitated with PFM crowns and in the test group, the subjects were rehabilitated with Zirconia crowns. Rehabilitation was done after the healing period of 3 months. Radiographic evaluation was done at regular (baseline, $3 \mathrm{rd}, 6^{\text {th }}$, and 12 th month) intervals.

Results The results were statistically analyzed. Keeping in mind the limitations of the study, it was revealed that the difference in the crestal bone resorption in both the groups was not significant.
\end{abstract}

\section{Introduction}

Evolution of dental sciences in the past years has reached unimaginable heights. In an earlier time, missing teeth were replaced by fixed partial dentures. ${ }^{1}$ The uniqueness of treating edentulism with implants lies in its capability to achieve the goals of function, esthetics, speech, and health. ${ }^{2}$ Dental implant has come up in a big way as an acceptable alternative to the traditional prosthetic treatment of rehabilitating single or multiple missing teeth. ${ }^{3}$ Osseo-integrated implants have emerged as a standard treatment of missing teeth. Over the past few years, guidelines such as insertion of implants with low trauma, minimal heating of the site, initial stability, etc., have been established for the purpose of successful treatment. ${ }^{4}$ The final outcome must also include appropriate soft and hard tissue levels. After the surgical insertion of implants and prosthetic loading, crestal bone undergoes remodeling and resorption process. To achieve this goal, each step must be performed with care. ${ }^{5}$
Soft tissue esthetics around natural teeth is based on biological width. This consists approximately $1 \mathrm{~mm}$ of epithelium and $1 \mathrm{~mm}$ of sulcus. ${ }^{6,7}$ This natural soft tissue seal avoids bone resorption. The resorption does not start as long as the implant is submerged, but after it is exposed to oral environment during the second stage. ${ }^{8}$

One reference criteria established for success of implant survival in marginal bone level change is that in the first year it should be $<1.5 \mathrm{~mm}$ and ongoing annual bone loss should be $<0.2 \mathrm{~mm}$. ${ }^{9}$ One of the basic notions of osseo-integeration was that the implant must be protected from shock of occlusal function or parafunction. Refraining from ceramic or even metal surfaces was assumed to be of critical importance. ${ }^{10}$ Ceramic systems have better biocompatibility and esthetic properties but its brittleness has led to more use of Zirconia-based ceramics in recent years. High-mechanical performance, durability, and resistance are the key features of Zirconia-based ceramics. The most widely used Zirconium oxide $\left(\mathrm{ZrO}_{2}\right)$ is Yttria tetragonal polycrystal (Y-TZP). ${ }^{11}$
License terms

ISSN 2321-1482.
DOI https://doi.org/ 
Patient expectations for esthetic restorations created the necessity to restore implants with more natural looking materials that would create less tension around implant and surrounding tissue. Therefore, the purpose of this study was to evaluate marginal bone loss around dental implants restored with Zirconium versus porcelain-fused-to-metal (PFM) prosthetic restorations.

\section{Materials and Methods}

\section{Materials}

1. Standard implants and prosthetic components-Adin (Touareg-S) (Israel).

2. Physio dispenser-Astratech (Italy).

3. Surgical kit-Adin(Israel).

4. Michigan 'O' Probe with Williams Markings-API (United States).

5. Paralleling kit-RINN: DENTSPLY(Australia).

6. SHICK FONA CDR(RVG) (Italy).

7. OrisWin DG Suite Software.

8. PFM prosthetic crown-Nickel-Chromium (Ni-Cr) alloy coping and veneering is done with VITA VMK Master (Germany).

9. Zirconia prosthetic crown Zenostar T-WIELAND ZENOSTAR of Ivoclar Vivadent (Germany).

\section{Methodology Inclusion Criteria}

1. Patients within age group of 20 to 40 years.

2. There should be absence of any systemic diseases.

3. Partially edentulous maxillary or mandibular arches (preferably mandibular posterior arch).

4. Adequate interarch space.

5. Adequate bone quality and quantity.

6. Patients with good oral hygiene.

\section{Exclusion Criteria}

1. A history that would complicate the outcome of the study, such as alcohol or drug dependency, smoking, poor health, or any other medical, physical or psychological reason that might affect the surgical procedure or the subsequent prosthodontics treatment and required follow-up.

2. Heavy smokers.

3. Poorly controlled diabetes mellitus.

4. Patients on radiotherapy.

5. Patients with temporomandibular disorders

Twenty-eight implants were placed in the mandibular arch, using a two-stage surgical technique in partially edentulous patients. The patients were divided into two groups.

Group I (control group): This group consists of 14 subjects who were rehabilitated with 14 implants. After the healing period of 3 months, implants were rehabilitated with PFM crowns.
Group II (test group): This group also consists of 14 subjects who were rehabilitated with 14 implants, but after the healing period of 3 months, implants were rehabilitated with Zirconia crowns.

The informed consent of the patient was taken before the surgery. The conventional two-stage implant surgical procedure was performed (-Fig. 1). After the healing period of 3 months, the flap was reopened to place the gingival former (-Fig. 2), which was followed by the impression procedure after the period of 7 to 14 days. At the end, subjects were rehabilitated according to the groups.

Monitoring at regular intervals was done, and four standardized radiographs with a paralleling kit (RINN Densply, Australia) (-Fig. 3) were taken at the baseline, 3rd month, 6 th month, and 12th month (-Fig. 4). The paralleling technique minimizes the image distortion and distortion in size.

The peri-implant soft tissue health was assessed by suitable indices at the 3rd month, 6th month, and 12th month. The indices chosen were as follows:

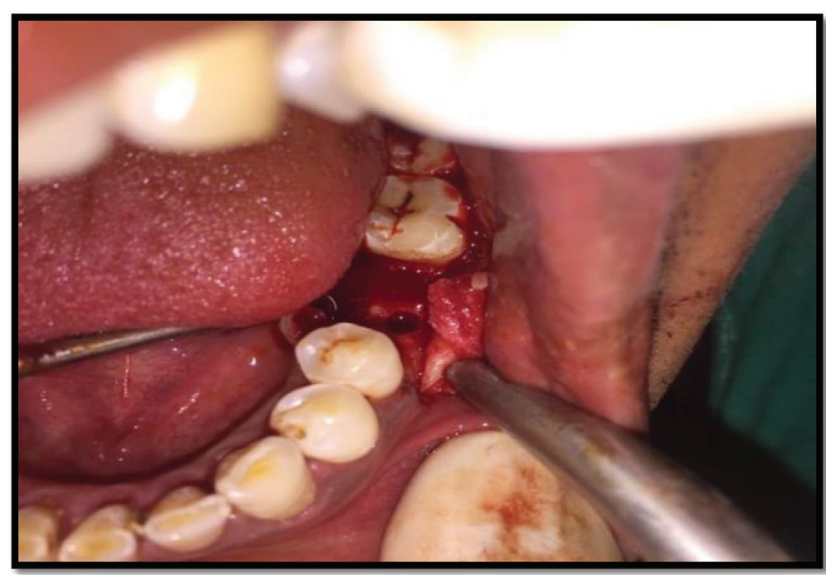

Fig. 1 Implant site.

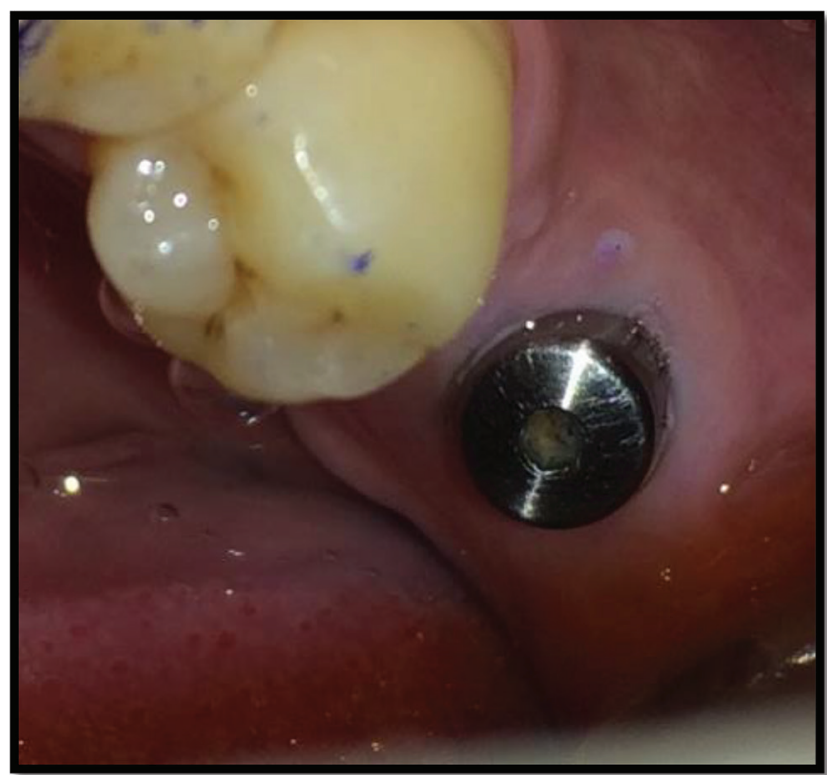

Fig. 2 Gingival former in place. 
1. Modified sulcular bleeding index (SBI).

2. Gingival index.

The bone loss was evaluated on both the mesial and distal aspects at all the four intervals. The master chart was prepared for the data and entered in the computer in Microsoft Excel format and was analyzed using SPSS version.

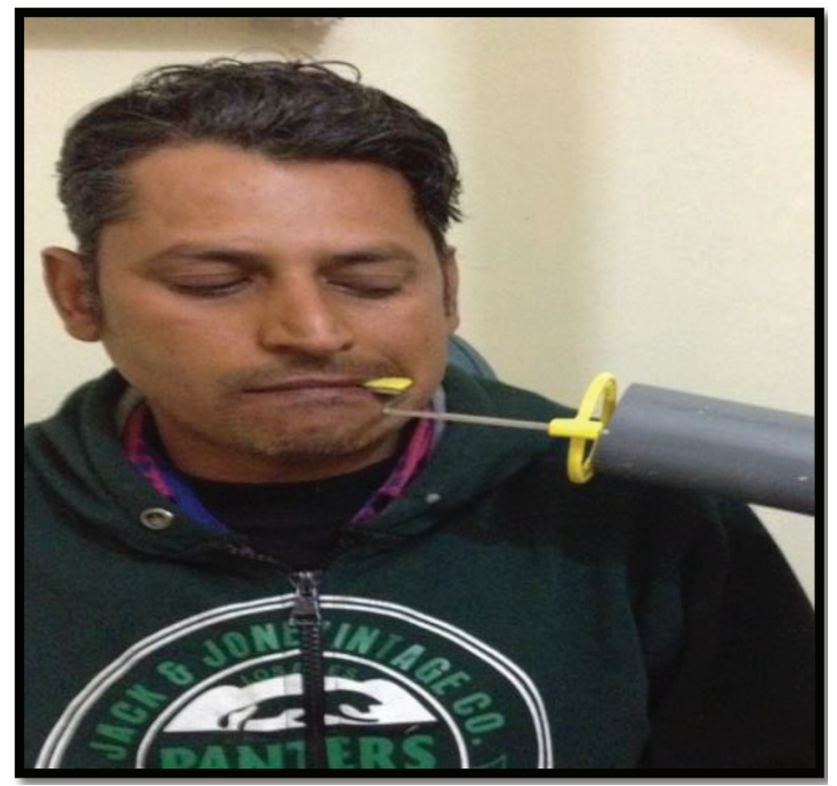

Fig. 3 IOPA technique with paralleling kit. IOPA, intraoral periapical.

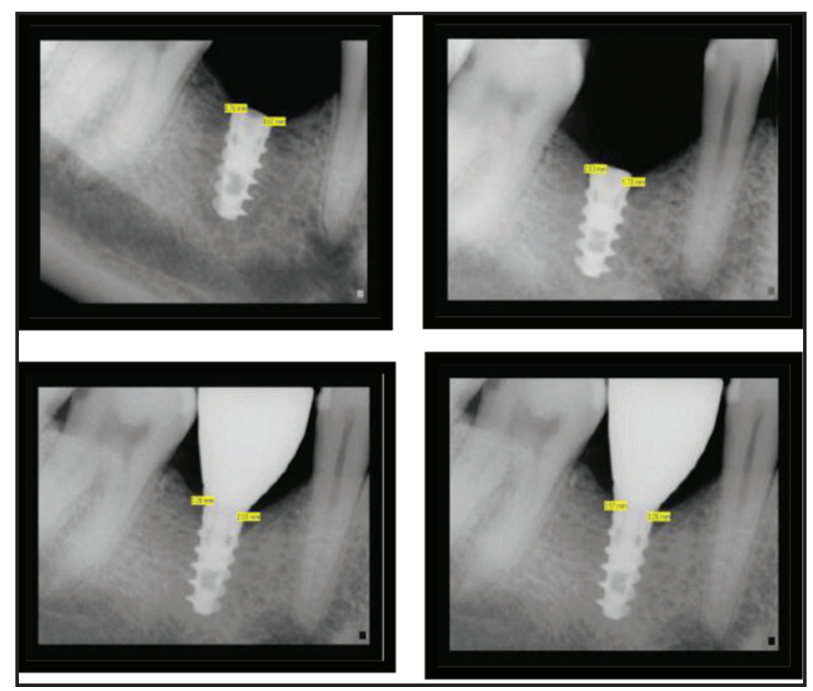

Fig. 4 Radiographs at baseline, 3rd, 6th, and 12th month.

\section{Results}

In a 1-year follow-up, all the patients completed the study. No superstructure complications such as chipping, fracture of restorative material, or implant complications such as peri-implantitis, mobility, implant loss and loosening of implant screw occurred. In all 28 patients, bone level was measured on mesial and distal aspects of the implant at regular intervals (baseline, 3rd month, 6th month, and 12th month) of implant insertion. The statistical analysis included mean and standard deviation, followed by the statistical test (unpaired $t$-test) and calculation of $p$-value. Comparisons were made between the two groups. Analysis for both mesial and distal sides was performed separately and the overall bone loss was calculated thereafter. Statistical tests were performed to see in which group the bone loss was significantly more.

The mean mesial bone loss for group I at baseline, 3rd month, 6th month, and 12th month were $1.64 \mathrm{~mm}, 2.11 \mathrm{~mm}$, $2.51 \mathrm{~mm}$ and $2.71 \mathrm{~mm}$, respectively. Similarly, mean mesial bone loss for group II was $0.61 \mathrm{~mm}, 0.97 \mathrm{~mm}, 1.51 \mathrm{~mm}$, and $1.85 \mathrm{~mm}$. For the distal side, the values for group I are $1.56 \mathrm{~mm}, 1.91 \mathrm{~mm}, 2.27 \mathrm{~mm}$, and $2.56 \mathrm{~mm}$. In the same way, the values for group II are $0.72 \mathrm{~mm}, 1.02 \mathrm{~mm}, 1.52 \mathrm{~mm}$, and $1.90 \mathrm{~mm}$. The comparison of the values between both the groups was done using the Mann-Whitney U test. There was no significance difference between the two ( - Fig. 5 and - Table 1).

The examination results for gingival index and mean SBI also came out to be nonsignificant (-Figs. 6 and 7).

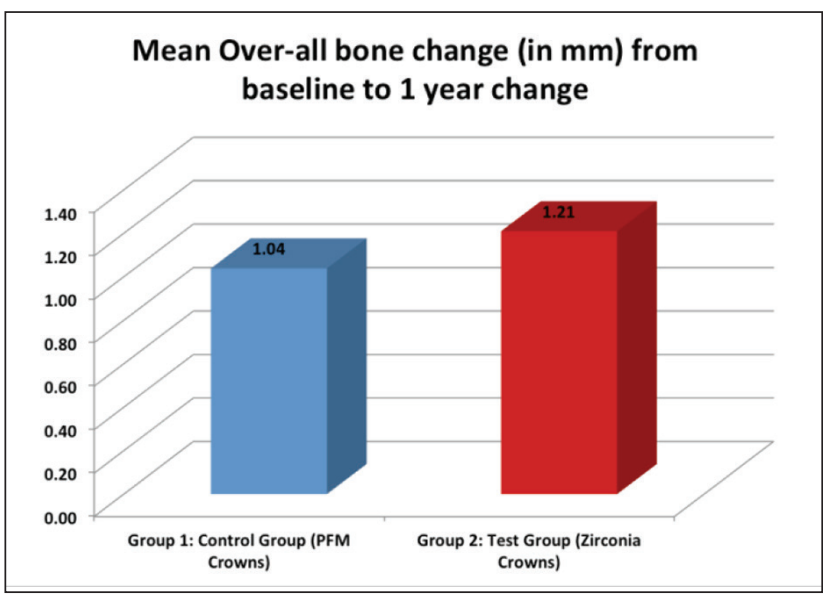

Fig. 5 Mean overall bone loss in both the groups.

Table 1 The comparison of mean overall bone loss between both the groups

\begin{tabular}{|l|l|l|l|l|l|l|}
\hline \multirow{2}{*}{ Group } & \multicolumn{5}{|c|}{ Overall (in mm) - 1 year change } \\
\cline { 2 - 7 } & Number & Mean & $\begin{array}{l}\text { Standard } \\
\text { deviation }\end{array}$ & $\begin{array}{l}\text { Mean } \\
\text { difference }\end{array}$ & t-test value & $p$-Value \\
\hline Group 1: control group (PFM crowns) & 14 & 1.04 & 0.60 & -0.17 & -0.719 & 0.479 \\
\hline Group 2: test group (zirconia crowns) & 14 & 1.21 & 0.66 & & & \\
\hline
\end{tabular}

Abbreviation: PFM, porcelain-fused-to-metal. 


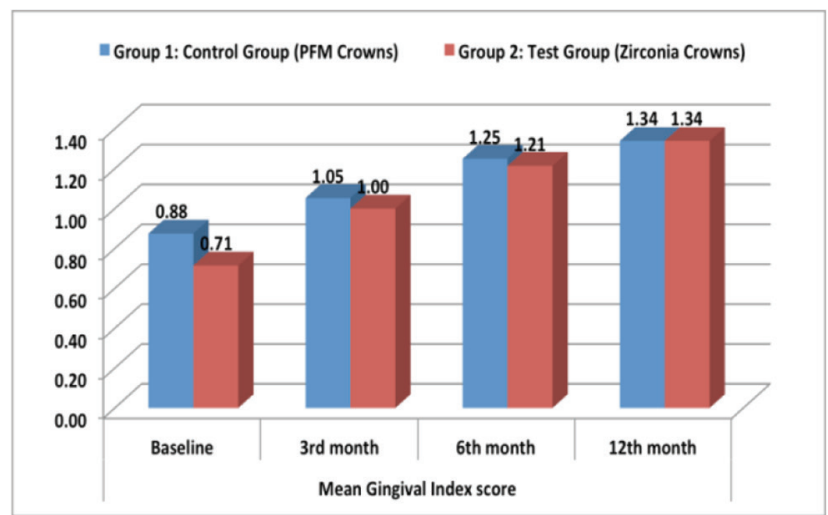

Fig. 6 Mean gingival index.

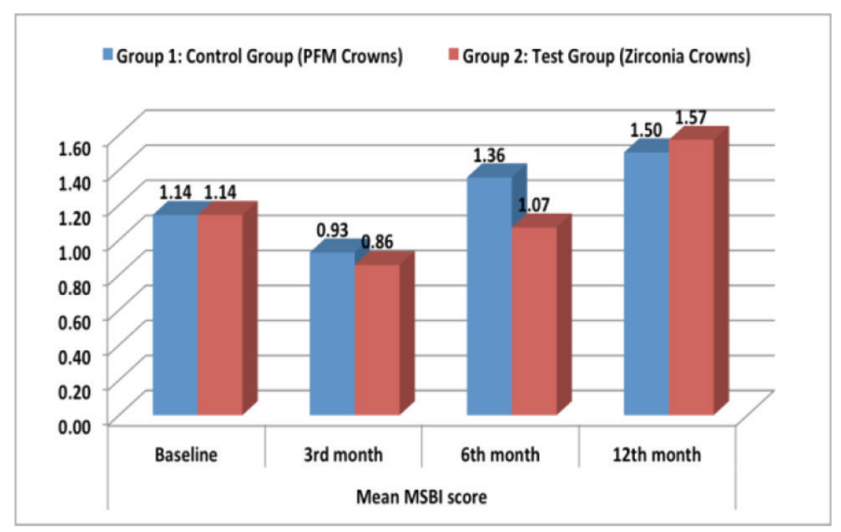

Fig. 7 Mean SBI score. SBI, sulcus blood index.

\section{Discussion}

This study was undertaken to compare the crestal bone loss in dental implants rehabilitated with different prosthetic materials (Zirconia and PFM). Standardized radiographs at the regular intervals (baseline, 3rd month, 6th month, and 12th month) were taken.

The methodology of obtaining radiographs was standardized with the long cone paralleling technique. The patient's position was standardized with the upper arch parallel to, and midsagittal plane perpendicular to the floor. ${ }^{12,13,14}$ For bone loss evaluation, first macro thread was taken as reference point to the crest of bone where it contacted the implant.

Misch et al in a 2008 study concluded that primary criteria for assessing implant quality and health are pain and mobility, with the next being uncontrolled progressive bone loss. ${ }^{15}$

None of the patient in this study reported any pain and the implants were healthy according to the above criteria.

In the last few years, a clear interest in utilization of Zirconia in implant prosthesis has been growing, but its long-time effects has not been completely investigated yet. Raigrodski in 2006 concluded in a clinical study that Zirconia-based, 3-unit fixed partial dentures (FPDs) demonstrated good performance in terms of clinical fracture, resistance, marginal integrity, and secondary decay. ${ }^{16}$ Meric et al in 2011 concluded in a study that stress levels on the bone surrounding the implants were less in the case of fiber-reinforced resin than PFM. ${ }^{17}$ In 2011, Gomes et al did a three-dimensional (3D) finite element analysis (FEA) which concluded the use of different materials to fabricate the superstructure for single implant-supported prosthesis did not affect the stress distribution in the supporting bone but the retention screw received less stress when a combination of porcelain and Zirconia was used. ${ }^{18}$ Similarly, Solimon et al in 2015 conducted a 3D FEA which concluded that soft prosthetic materials absorb more energy from the applied load and transfers less energy to the bone. Therefore, softer the material, better it is. ${ }^{19}$

In the current study, bone levels individually on the mesial and distal aspects were analyzed. For both overall mesial and distal bone loss $p$-value was 0.496 and 0.484 , respectively which was not significant $(p>0.005)$. Similarly, mean overall bone loss when compared between two groups from baseline to 12 th month, the $p$-value was 0.479 which was not significant.

Thus, from the statistical analysis, there is no significant difference between the bone loss between the implants rehabilitated with PFM crowns and Zirconia crowns. The results of the study are not similar to a study conducted by Turk et al who performed a clinical trial to show the crestal bone loss around dental implants could be influenced by using Zirconia crowns over implants. He stated that implants rehabilitated with Zirconia crowns showed less bone loss as compared with those rehabilitated with PFM crowns. ${ }^{10}$

The two indices chosen to assess the clinical health of gingiva were gingival index and mean SBI. The statistical findings for both the control group and the test group came out to be not significant.

\section{Conclusion}

Keeping in mind the limitation of this study, it is concluded that the bone loss was not significant in PFM crowns group as compared with the Zirconia crowns group. Even the evaluation of periodontal indices revealed no significance difference between the two groups. At present there is very limited number of reports on different prosthetic materials; therefore, the scientific evidence on this topic is lacking in both quantity and quality. Therefore, longitudinal randomized controlled trials with larger sample size are needed to substantiate the predictability of the effect of different crown materials on the crestal bone loss.

\section{Funding \\ None.}

\section{Conflict of Interest}

None declared.

\section{References}

1 Singh P, Garge HG, Parmar VS, Viswambaran M, Goswami MM. Evaluation of implant stability and crestal bone loss around the implant prior to prosthetic loading: A six month Study. J Indian Prosthodont Soc 2006;6(1):33-37 
2 Carl E, Misch. Rationale for Dental Implants. Contemporary Implant Dentistry 3rd ed. Philadelphia, Pennsylvania: Elsevier Mosby 2005;197-205

3 Sheikh MA, Shafiq S, Mehdi A, Riaz M. Success \& evaluation of dental implant patients at Islamic International Dental College \& Hospital. Pak Oral Dent J 2012;32(1):10-15

4 Zinsli B, Sägesser T, Mericske E, Mericske-Stern R. Clinical evaluation of small-diameter ITI implants: a prospective study. Int J Oral Maxillofac Implants 2004;19(1):92-99

5 JangJ-B, PenalM, EskowR, ElianN, ChoS-C. The Effect of Implant Design on Crestal Bone Levels. Presented at: 23rd Annual Meeting of Academy of Osseointegration, Boston, 2008; 221-234

6 Cappiello M, Luongo R, Di Iorio D, Bugea C, Cocchetto R, Celletti R. Evaluation of peri-implant bone loss around platform-switched implants. Int J Periodontics Restorative Dent 2008;28(4):347-355

7 Vacek JS, Gher ME, Assad DA, Richardson AC, Giambarresi LI. The dimensions of the human dentogingival junction. Int J Periodontics Restorative Dent 1994;14(2):154-165

8 Hermann JS, Buser D, Schenk RK, Schoolfield JD, Cochran DL. Biologic width around one- and two-piece titanium implants. Clin Oral Implants Res 2001;12(6):559-571

9 Albrektsson T, Chrcanovic B, Östman PO, Sennerby L. Initial and long-term crestal bone responses to modern dental implants. Periodontol 2000 2017;73(1):41-50

10 Türk AG, Ulusoy M, Toksavul S, Güneri P, Koca H. Marginal bone loss of two implant systems with three different superstructure materials: a randomised clinical trial. J Oral Rehabil 2013;40(6):457-463

11 Sinem S, Deger O, Bulent S. Effects of surface treatments and repeated firings on bond strength of zirconia and veneer ceramics. Int J Educ Res (Dhaka) 2016;4(3):101-114
12 Fernández-Formoso N, Rilo B, Mora MJ, Martínez-Silva I, Díaz-Afonso AM. Radiographic evaluation of marginal bone maintenance around tissue level implant and bone level implant: a randomised controlled trial. A 1-year follow-up. J Oral Rehabil 2012;39(11):830-837

13 Job S, Bhat V, Naidu EM. In vivo evaluation of crestal bone heights following implant placement with 'flapless' and 'withflap' techniques in sites of immediately loaded implants. Indian J Dent Res 2008;19(4):320-325

14 Chugh A, Nandal S. Original research radiological evaluation of marginal bone around dental implants: A pilot study. Eur J Prosthodont 2014;2(2):58-61

15 Misch CE, Perel ML, Wang HL, et al. Implant success, survival, and failure: the International Congress of Oral Implantologists (ICOI) Pisa Consensus Conference. Implant Dent 2008;17(1):5-15

16 Raigrodski AJ, Chiche GJ, Potiket N, et al. The efficacy of posterior three-unit zirconium-oxide-based ceramic fixed partial dental prostheses: a prospective clinical pilot study. J Prosthet Dent 2006;96(4):237-244

17 Meric G, Erkmen E, Kurt A, Eser A. Influence of Prostheses type and materials on Stress Distribution in Bone Around Implants: A 3D FEA Analysis. J Dent Sci 2011;6:25-30

18 Gomes ÉA, Barão VA, Rocha EP, de Almeida ÉO, Assunção WG. Effect of metal-ceramic or all-ceramic superstructure materials on stress distribution in a single implant-supported prosthesis: three-dimensional finite element analysis. Int J Oral Maxillofac Implants 2011;26(6):1202-1209

19 Soliman T, Tamam R, Yousief S. Assessment of stress distribution around Implant fixture with 3 different crown materials. Tanta Dental Journal 2015;12:249-258 